\title{
DORSOLATERAL ONLAY URETHROPLASTY FOR THE LONG SEGMENT ANTERIOR URETHRAL STRICTURE: OUTCOME OF 31 CASES
}

\author{
HAFIZ AL-ASAD ${ }^{1}$, MD. SHARIF SHAHJAMAL ${ }^{2}$, SARFORAJ ALI KHAN ${ }^{3}$, MD. WALIUL ISLAM ${ }^{4}$, \\ AKM ZAMANUL ISLAM BHUIYAN ${ }^{5}$
}

${ }^{1}$ Registrar, Dept. of Urology, Dhaka Medical College Hospital, ${ }^{2}$ Assistant Professor, Dept. of Urology, National Institute of Kidney Diseases and Urology, Dhaka, ${ }^{3}$ Assistant Professor, Dept. of Urology, National Institute of Kidney Diseases and Urology, Dhaka, ${ }^{4}$ Associate Professor, Dept. of Urology, National Institute of Kidney Diseases and Urology, Dhaka, ${ }^{5}$ Professor, Dept. of Urology, National Institute of Kidney Diseases and Urology, Dhaka

\begin{abstract}
:
Objective: This study is designed to observe the short-term outcomes of dorsolateral onlay urethroplasty to treat long segment anterior urethral stricture.

Materials and Methods: A prospective study from May 2011 to September 2012 is carried out in department of Urology, National Institute of Kidney Diseases and Urology, Sher-EBanglanagar, Dhaka. Thirty one patients with long anterior urethral stricture were treated by a dorsolateral onlay buccal mucosa graft. After voiding trial, they were followed up at 3 weeks and 3 months with history, physical examination, uroflowmetry and retrograde urethrogram $(R G U)$ if required (uroflowmetry $<15 \mathrm{ml} / \mathrm{sec}$ ). Patients were further followedup at 3 months interval with uroflowmetry and retrograde urethrogram (RGU) if required (uroflowmetry $<15 \mathrm{ml} / \mathrm{sec}$ ). Successful outcome was defined as normal voiding with no surgical intervention after catheter removal.
\end{abstract}

Results: Mean stricture length was 42.49 $\pm 12.77 \mathrm{~mm}$ (range 24-70 $\mathrm{mm}$ ) and mean follow up was 8 months (range 6 to 12 months). Three patients were found to develop stricture at anastomotic site, during follow-up and required optical internal urethrotomy and was considered as failure. One patient developed wound infection which resolved after regular dressing. Success rate was $90.32 \%$.

Conclusion: Dorsolateral onlay BMG urethroplasty is feasible for long anterior urethral stricture with good short term surgical outcome.

Key words: Urethral stricture, Buccal mucosal graft (BMG), Retrograde urethrogram (RGU), Voiding cystourethrogram (VCUG), Optical internal urethrotomy (OIU).

Bangladesh J. Urol. 2015; 18(1): 12-15

\section{Introduction}

Urethral stricture is one of the oldest known urological diseases and remains a common problem with high morbidity. The urethral strictures are fibrotic narrowing composed of dense collagen and fibroblasts. Fibrosis usually extends into the surrounding corpus spongiosum, causing spongiofibrosis[1]. The treatment of urethral strictures varies according to location, length, depth and density of the stricture. Optical internal urethrotomy (OIU) may be useful for short annular strictures, but this procedure is associated to a very

Correspondences: Hafiz Al-Asad, Registrar, Dept. of Urology, Dhaka Medical College Hospital. E-mail: hafizalasad34@yahoo.com high recurrence rate[2]. Urethral reconstruction with excision of the strictured segment and end-to-end anastomosis is successful in more than $95 \%$ of patients with a stricture of up to $2 \mathrm{~cm}$ in length[3]. Patients with long strictures ( $>2 \mathrm{~cm}$ in length) are not suitable for end-to-end urethroplasty due to the risk of postoperative chordee formation[4]. Substitution urethroplasty is ideal for the management of long anterior urethral strictures. The ideal material for substitution urethroplasty remains controversial[5]. Urethral substitution has long been accomplished by using genital skin flaps, grafts of genital or extragenital tissue[6]. Currently, buccal mucosa graft substitution urethroplasty is the most preferred option 
for long bulbar urethral strictures. Buccal mucosa offers the advantages of being accustomed to a wet environment, having good vascularity, hair less, easy to harvest, thick epithelium making it easy to handle and less chance of graft contracture, having a thin lamina propria allowing early inosculation, reduced rate of pseudo-diverticulum formation[5]. Whether to place the graft dorsally, ventrally or laterally is still controversial. Dorsal onlay graft procedure provides the advantages of better mechanical support by the corporal bodies with fewer incidences of sacculation and fistula formation but this approach may damage erectile function and the bulbar arteries when the dissection from the corpora needs to be very proximal[7]. As dorsal onlay urethroplasty requires circumferential mobilization of the urethra, this might cause ischemia of the urethra in addition to chordee. But in dorsolateral technique urethra was not separated from the corporal bodies on one side and was only mobilized from the midline on the ventral aspect to beyond the midline on the dorsal aspect. The urethra was opened in the dorsal midline over the stricture. The buccal mucosal graft was secured on the ventral tunica of the corporal bodies. In this study, we adopt this technique and tried to evaluate the short term outcome.

\section{Materials and Methods}

From May 2011 to September 2012, thirty one patients with long anterior urethral stricture were managed by single stage urethroplasty with a dorsolateral onlay patch BMG. Each patient was evaluated with history, physical examination, uroflowmetry, imaging study with retrograde urethrogram (RGU) and voiding cystourethrogram (VCUG) and other routine investigations required for anaesthetic fitness. All the patients were selected purposively according to the selection criteria that were, patients having primary and recurrent stricture of anterior urethra, stricture length more than $2 \mathrm{~cm}$, patients with significant lower urinary tract symptoms and patient given consent for operation and record for study purpose. Stricture involving posterior urethra and with oral pathology were excluded. Ethical committee's approval was taken to perform the study. Operation was performed under general anesthesia with naso-tracheal intubation and the patient was put in exaggerated lithotomy position. Operation was done in a 2-team approach-one team engaged in urethral procedure and other team in harvesting the buccal mucosa. Through a midline perineal incision, the bulbo-cavernosus muscle was divided exposing the corpus spongiosum of the anterior urethra. Then the anterior urethra was easily dissected from corpora cavernosa. Then the strictured segment of the urethra was identified. The other team then harvested the buccal mucosal graft of adequate length, from the inner cheek area below the Stensen's duct without injuring it. Lignocaine (2\%) with adrenaline (1:200000) was injected into the edges of the desired graft length before harvesting to get better hemostasis. Graft donor site is closed with continuous 4-0 chromic catgut sutures to achieve good haemostasis. The graft was then defatted and tailored to its proper size. The dissected urethra was not separated from the corporal bodies on one side and was only mobilized from the midline on the ventral aspect to beyond the midline on the dorsal aspect. The urethra was opened in the dorsal midline over the stricture. The proximal and distal urethral lumens of the urethra were calibrated. The right margin of the graft was sutured with the urethral margin using 5-0 polyglactin suture. Foley catheter was inserted through the urethra into the urinary bladder. Then the left margin of the urethral mucosa was sutured to the graft using 50 polyglactin continuous suture. Few interrupted stitches were given to fix the buccal mucosal graft to secure on the ventral tunica of the corporal bodies. Suprapubic catheterization was done in all patients. The patient was maintained on antibiotics until the catheter was removed. Three weeks after the operation the urethral catheter was removed if patient could void well then the suprapubic catheter was removed on the next day. All the patients were advised to visit at outpatient door on 3 weeks and on 3 months for follow up. During follow up patient's history, physical examination, uroflowmetry were done. If uroflowmetry showed significant obstruction ( $<15 \mathrm{ml} /$ $\mathrm{sec}$ ) then retrograde urethrogram (RGU) and voiding cystourethrogram (VCUG) was done. A successful outcome was defined as normal voiding with no need of any kind of surgical inervention. Patients were further followed-up at 3 months interval with uroflowmetry and RGU and VCUG if required (uroflowmetry $<15 \mathrm{ml} / \mathrm{sec}$ ).

\section{Results}

Total 31 patients, mean age $36.55 \pm 8.36$ years (range 21-53 years) had undergone BMG urethroplasty by dorsolateral onlay graft from May 2011 to September 2012. Most of the patients presented with poor flow of urine, some presented with per-urethral discharge and few of them presented with acute retention of urine. Cause of stricture was inflammatory $61.29 \%$, idiopathic $25.81 \%$, traumatic $6.45 \%$ and iatrogenic $6.45 \%$. Highest number of strictures 14 (45.16\%) were located in the bulbar part, penile urethral strictures were 10 (32.26\%) 
and 07 (22.58\%) strictures involved both bulbar and penile part. Mean stricture length was $42.49 \pm 12.77 \mathrm{~mm}$ (range 24-70 mm). Before surgery mean peak urinary flow rate was $6.68 \pm 1.35 \mathrm{ml} / \mathrm{sec}$. Mean operative time was 110 min (range 100 to $160 \mathrm{~min}$ ) and mean follow-up was 8 months (range 6-12 months). All patients required peroperative blood transfusion but no patients required it postoperatively. Thirty patients were discharged on $4^{\text {th }}$ post-operative day, only one patient how developed wound infection was managed successfully with change in antibiotics as per wound swab culture sensitivity test and regular dressing and was discharged on $14^{\text {th }}$ postoperative. On urethral catheter removal of that patient, he could void well and needed no intervention. On follow up peak urinary flow rate improved significantly. At 3 weeks and at 3 months the mean peak urinary flow rate was $20.00 \pm 3.20$ and $20.19 \pm 3.45 \mathrm{ml} / \mathrm{sec}$ respectively. Two patients developed stricture at proximal anastomotic site which was addressed during follow up and required optical internal urethrotomy and was considered as failure. In our series the mean follow up was 8 months (range 6 to 12 months). In this study the success rate was $90.32 \%$ (28 patients) and failure rate was $9.68 \%$ (3 patients).

\section{Discussion}

Urethral strictures were documented in ancient literature dating from Greek and Egyptian period. Continuous attempts are made in different parts of the world in different centers to find out an ideal method of treatment according to the merit of individual type of stricture. Significant progress made over the last 30 years[8]. A circumferential dissection of the whole anterior urethra risks the vascularity of the urethra, which may be more important if the meatus is involved with disease and the distal-most urethra is extensively dissected, such as is seen with concomitant lichen sclerosis. The Barbagli procedure with circumferential mobilization of the urethra for dorsal onlay patch has a success rate of $99 \%$ in the short-term[9]. However, in long segment anterior urethral strictures, circumferential urethral mobilization may jeopardize the lateral vascularity of the urethra. Barbagli also described the lateral onlay procedure with results similar to dorsal and ventral onlay for bulbar urethral strictures[10]. Asopa's procedure of inlay patch by ventrally incising the urethra is another option for anterior urethral strictures[11]. It preserves the lateral vascularity of the urethra. However, it has two potential drawbacks. Firstly, a wider graft may be difficult to be placed using this approach and may likely get folded. Secondly, we do not know how the long ventral saggital incision on the scarred urethra will behave in the long-term followup. In the short-term follow-up, this procedure has shown good results[11,12]. To maintain the urethral vascularity on one side of the urethra while keeping the graft in a dorsolateral onlay fashion, we adopted the policy of limited urethral mobilization, i.e., from ventral midline to beyond dorsal midline. In this procedure, the vascular supply of the urethra of the other side is maintained. We kept the grafts of up to $20 \mathrm{~mm}$ in width with a maximum length from 24 to $70 \mathrm{~mm}$. Technically, it is as easy as the Barbagli procedure. It also preserves the one-sided bulbar artery in addition to maintaining the native lateral vascularity at the distal urethra. Furthermore, by using this approach, we did not find postoperative chordee in any case. In this procedure, the urethra is not completely mobilized off the corpora; hence, graft sizing is more appropriate, preventing the chordee. We cannot comment on postoperative sexual and ejaculatory function as we specifically did not look into this matter. Muscle and nerve sparing onlay patch urethroplasty have been suggested for better ejaculatory function and to avoid post void dribbling[13]. None of our patients reported post void dribbling. The success rate of our study is similar to other studies[9,13]. In our series short-term results for the long segment anterior urethral strictures are reasonable.

\section{Conflict of Interest : None Declared}

\section{References}

1. McAninch JW. Disorders of the penis and male urethra. In: Tanagho, EA, McAninch, JW, eds. Smith's general urology. $17^{\text {th }}$ ed. West Patel Nagar, New Delhi: Tata McGraw-Hill Co. 2009; 625637.

2. Heyns CF, Steenkamp JW, DeKock ML, Whitaker $P$. Treatment of male urethral strictures: is repeateddilation or internal urethrotomy useful?. J Urol. 1998; 160: 356-8.

3. Webster GD, Robertson CN. The vascularized skinisland urethroplasty: its role and results in urethralstricture management. J Urol. 1985; 133: 31-3.

4. Gupta NP, Ansari MS, Dogra PN, Tandon S. Dorsal buccal mucosal graft urethroplasty by a ventral sagittal urethrotomy and minimal-access perineal approach for anterior urethral stricture. BJU Int. 2004; 93: 1287-90.

5. Bhargava S, Chapple CR. Buccal mucosalurethroplasty: is it the new gold standard?. BJU Int. 2004; 93: 1191-3. 
6. Morey AF, McAninch JW. Techniques of harvesting buccal mucosa for urethral reconstruction. J Urol. 1996; 155: 1696.

7. Iselin CE \& Webster GD. Dorsal onlay graft urethroplasty for repair of bulbar urethral strictures. J Urol. 1999; 161: 815-18.

8. Jordan $\mathrm{GH}$, Schlossberg SM. Surgery of the penis and urethra. In: Wein AJ, Kavoussi LR, Novick, AC, Partin AW, Peter CA, eds. Campbell's Urology. $9^{\text {th }}$ ed. Philadelphia: Saunders. 2007; 1023-1097.

9. Barbagli G, Morgia G, Lazzeri M. Dorsal onlay skin graft bulbar urethroplasty: Long-term follow-up. Eur Urol. 2008; 53: 628-33.

10. Barbagli G, Palminteri E, Guazzoni G, Montorsi F, Turini D, Lazzeri M. Bulbar urethroplasty using buccal mucosa grafts placed on the ventral, dorsal or lateral surface of the urethra: Are results affected by the surgical technique? J Urol 2005; 174 : 955-7.

11. Asopa HS, Garg M, Singhal GG, Singh L, Asopa J, Nischal A. Dorsal free graft urethroplasty for urethral stricture by ventral sagittal urethrotomy approach. Urology. 2001; 58: 657-9.

12. Pisapati VL, Paturi S, Bethu S, Jada S, Chilumu $R$, Devraj R, et al. Dorsal buccal mucosal graft urethroplasty for anterior urethral stricture by asopa technique. Eur Urol. 2008. Jun 9. 2008 Jun 9. [Epub ahead of print]

13. Barbagli G, De Stefani S, Annino F, De Carne C, Bianchi G. Muscle and nerve-sparing bulbar urethroplasty: A new technique. Eur Urol. 2008; 54: 335-43.

Abbreviations:

OIU : Optical internal urethrotomy

RGU : Retrograde urethrogram

VCUG : Voiding cystourethrogram 